\title{
Clinical Reasoning: A 61-year-old woman with acute onset dysgraphia
}

LaTangela R. Smith, DO, Necrisha N.C. Roach, MD, MSc, and Sherita Chapman Smith, MD

Neurology ${ }^{\circledR}$ 2019;92:e386-e391. doi:10.1212/WNL.0000000000006821

\section{Section 1}

A 61-year-old right-handed woman presented to the emergency department after development of acute change in handwriting. The patient was at home in her usual state of health when she suddenly felt compelled to write something. When she began to write, she noted a change in

\author{
Correspondence \\ Dr. L.R. Smith \\ LaTangela.Smith@ \\ vcuhealth.org
}

Figure 1 Initial writing samples

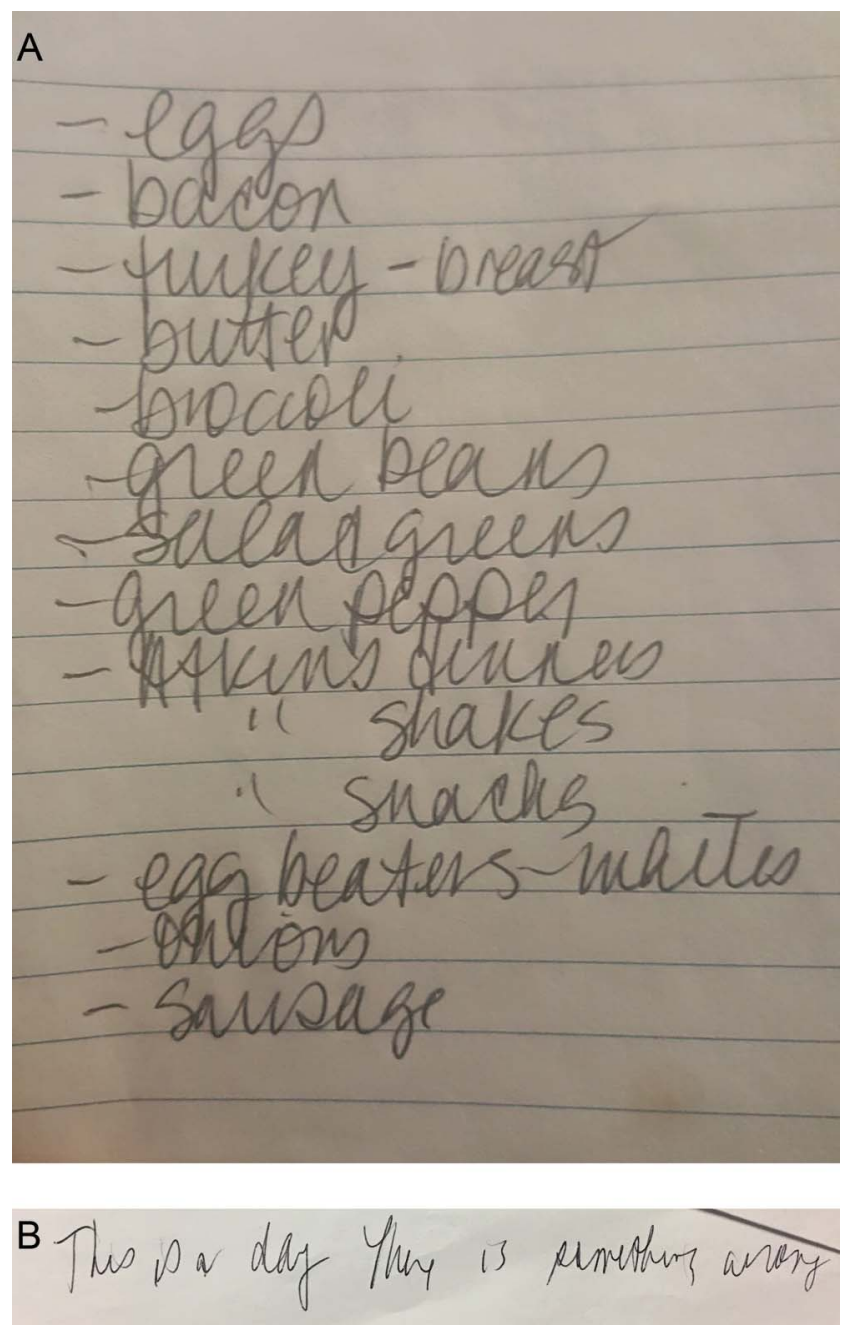

(A) Photograph of baseline writing sample. (B) Photograph of handwriting attempt when the patient was asked to write a sentence during emergency room bedside examination.

From the Virginia Commonwealth University Health System (L.R.S., N.N.C.R., S.C.S.), Virginia Commonwealth University (S.C.S.), Richmond.

Go to Neurology.org/N for full disclosures. Funding information and disclosures deemed relevant by the authors, if any, are provided at the end of the article. 
handwriting (figure 1). She stated "I just couldn't get it to look right." Simultaneously, she also noted numbness over the right tip of her tongue.

On further questioning, it was noted that the patient had a history of cardiomyopathy with an ejection fraction of $25 \%$ status post automated implantable cardioverter defibrillator (AICD) placement and mitral insufficiency status post 2 bovine, mitral valve replacements with the most recent being within 3 weeks of symptom onset. There was also a remote history of atrial fibrillation. The patient was not on anticoagulation and was only taking daily aspirin.

\section{Questions for consideration:}

1. What is the differential diagnosis for acute onset dysgraphia?

2. What key examination findings should be assessed for in a patient with dysgraphia? 


\section{Section 2}

When taking into consideration the acuity of symptoms and the patient's cardiac history, the highest suspicion is for acute cerebral ischemia. In this setting, the most likely explanation is an acute or worsening subacute central process. For instance, in addition to ischemia, a small cerebral hemorrhage or enlargement of an intracerebral mass may produce this clinical scenario.

In a patient with dysgraphia, the examination would most likely be remarkable for a language, motor, or sensory deficit involving weakness or apraxia. A detailed assessment of language, motor, and sensory function of the dominant upper extremity should be completed.

The patient's physical examination at the time of initial presentation revealed the following:

Vitals: temperature $36.4^{\circ} \mathrm{C}\left(97.5^{\circ} \mathrm{F}\right)$, blood pressure $89 /$ $52 \mathrm{~mm} \mathrm{Hg}$, heart rate 73 , respiration rate $15, \mathrm{SpO}_{2} 98 \% \mathrm{RA}$.

General examination was unremarkable.

Mental status was normal. Speech was fluent. Naming, repetition, reading, and ability to follow complex commands were all intact. Handwriting continued to be affected with notable decline in penmanship. Ability to correctly hold pen, hand dexterity, and ability to initiate motion of writing remained intact. A mild, lingual dysarthria was noted.

Cranial nerves were intact except for mild flattening of the right nasolabial fold.

Patient had 5/5 strength proximally and distally in all extremities. Bulk and tone were normal. No abnormal movements were observed.

Sensation was intact to light touch, temperature, and vibration.

Deep tendon reflexes were nonpathologic. The patient had flexor plantar responses bilaterally.

Finger-nose-finger and rapid alternating movements were intact without dysmetria, ataxia, or slowing.

NIH Stroke Scale (NIHSS) score was 2 for mild dysarthria and flattening of right nasolabial fold.

\section{Question for consideration:}

1. Based on examination findings, what further testing would you consider?

\section{GO TO SECTION 3}




\section{Section 3}

Based on the patient's history of cardiac disease, presenting symptoms, and neurologic deficits, the decision was made to proceed with the institution's stroke protocol. A noncontrast head CT was completed to rule out intracranial hemorrhage and assess for any early signs of cerebral ischemia. Head CT was unremarkable. The patient then underwent vessel imaging including standard head and neck CT angiogram (CTA), CT perfusion (CTP) and RAPID CTP. CTA did not demonstrate any vessel occlusion or flow-limiting stenosis; however, on CTP, the patient had increased time to drain within the anterior left frontal lobe (figure 2). RAPID CTP confirmed standard CTP findings.

\section{Questions for consideration:}

1. Based on imaging and localization of symptoms, does the patient meet inclusion criteria for tissue plasminogen activator $(\mathrm{tPA})$ ?

2. Do the patient's symptoms localize to the area of perfusion deficit?

Figure 2 Rapid CT perfusion study

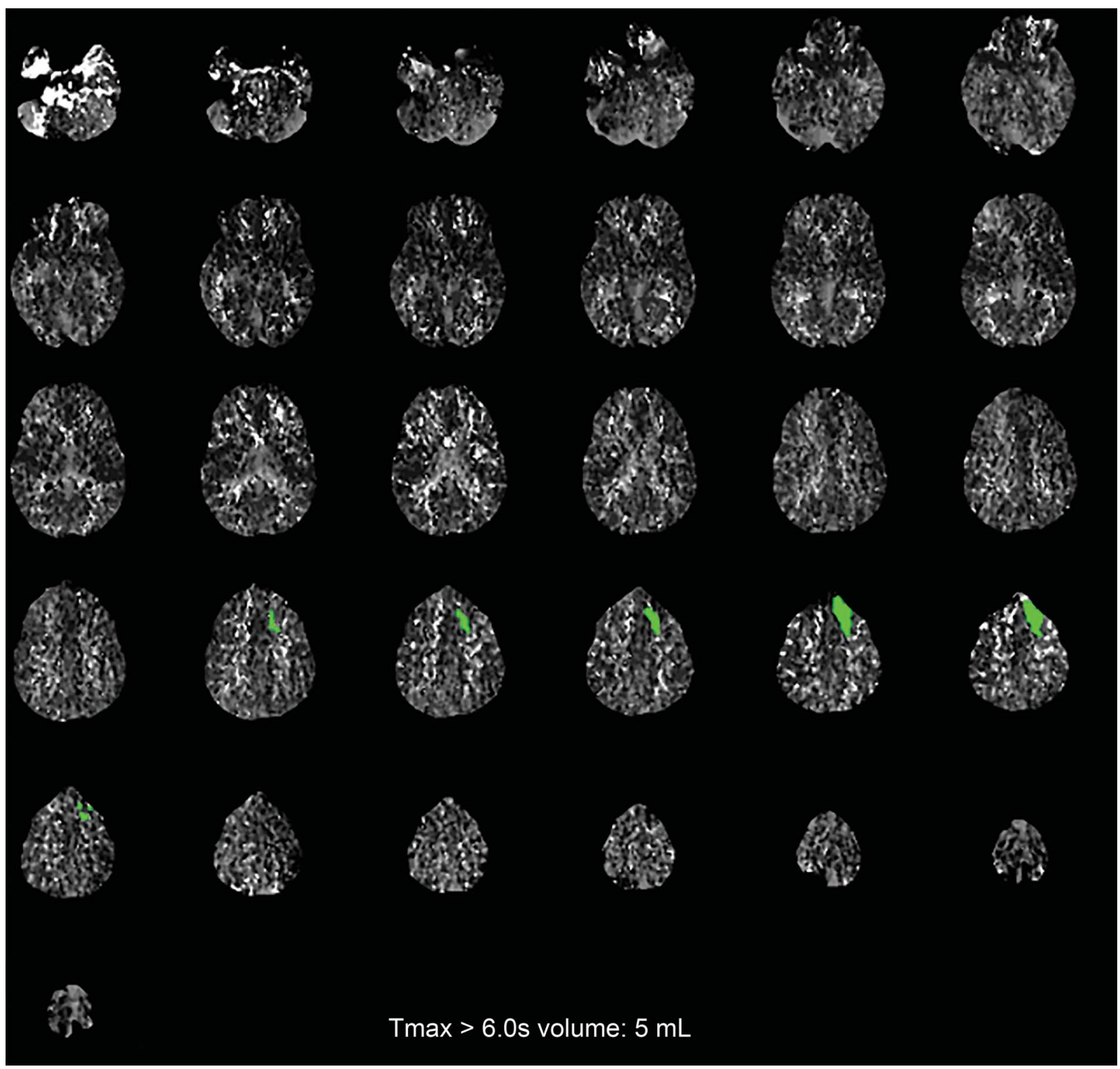

The green area represents a $5 \mathrm{~mL}$ segment of increased Tmax within the medial aspect of the anterior left frontal lobe corresponding with involvement of the left superior frontal sulcus.

GO TO SECTION 4 


\section{Section 4}

The patient's most prominent deficit at the time of the initial presentation was a change in handwriting. With the additional examination findings, presentation was highly concerning for an acute ischemic process. However, given the subtlety of examination findings, the results of the CTP were key in the decision to not exclude the patient from tPA.

Within 12 hours of tPA administration, the patient noted that tongue numbness resolved. The patient did not attempt to write again until the next morning on evaluation by neurology. This was $12-24$ hours post-tPA administration. At this time, the patient noted that her handwriting had returned to normal (figure 3). In addition, flattening of the right nasolabial fold and dysarthria had also resolved.

In a right-hand dominant individual, symptoms of dysarthria, right nasolabial flattening, and sensory deficit involving the right anterior tongue localize to the left frontal and parietal lobes or internal capsule. These symptoms when present simultaneously are classically believed to localize to the left sensorimotor tract, which travels through the aforementioned areas. As these tracts also funnel down through the brainstem and rely on thalamic relay, it could also be argued that symptoms could localize to either the internal capsule or thalamus. Initially, it was unclear if the dysgraphia localized given intact strength, sensation, and coordination of right upper extremity.

CTP demonstrated increased time to drain within the medial aspect of the anterior left frontal lobe. In 1881, Sigmund Exner introduced the concept of handwriting being localized to the medial frontal gyrus. ${ }^{1}$ This area has since been termed the Exner area. Support for this idea has been obtained through documented cases of cerebral infarction within the Exner area resulting in handwriting disturbances, whether involving change in formation of letters, letter/word substitution, difficulty with sentence formulation, or complete agraphia. ${ }^{2}$ From this it can be speculated that handwriting is not solely reliant on intact language and upper extremity

Figure 3 Pre and post tissue plasminogen activator (tPA) writing sample
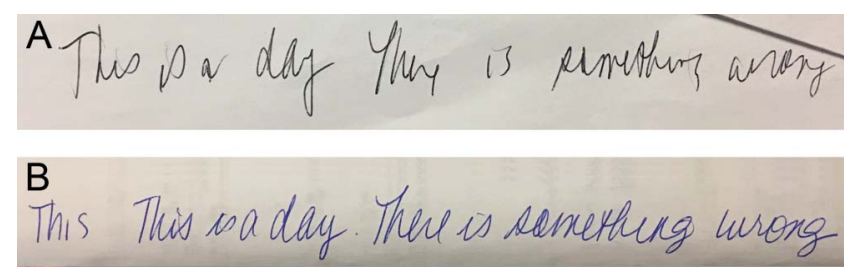

(A) Bedside writing sample on arrival to emergency room demonstrates decline in penmanship. (B) Bedside writing sample on hospital day 2 approximately 12-24 hours post-tPA demonstrates return to baseline penmanship. motor and sensory functions as cortically these functionalities localize to the Broca area (left inferior frontal gyrus), Wernicke area (left posterior superior temporal gyrus), arcuate fasciculus (posterolateral aspect of the left frontal lobe and superolateral aspect of the left parietal lobe), and sensorimotor tract controlling the upper extremity. The Exner area is distinct from all of these locations. Though the patient's perfusion imaging does not demonstrate compromise exactly within the Exner area, it does demonstrate tissue compromise within an additional area found to be essential for handwriting. This is the left superior frontal sulcus. In a meta-analysis published in 2013, it was found that writing-specific cortical areas include the left superior frontal sulcus, middle frontal gyrus (Exner area), left intraparietal sulcus, superior parietal area, and right cerebellum. ${ }^{3}$

Though the results of the patient's CTP explained her writing deficit, they did not explain the other findings noted on examination. As stated above, these findings localize to the left sensorimotor tract, which does not travel through the superior frontal sulcus.

\section{Discussion}

Given the acuity of dysgraphia and results of the CTP, it is most likely that the patient had acute ischemia within the left superior frontal sulcus. However, the numbness over the right, anterior tongue, lingual dysarthria, and flattening of the right nasolabial fold do not localize. Given the patient's cardiac history placing her at high risk for cardioembolic events, there is high suspicion that the patient had small, multifocal areas of acute ischemia within the left frontal and parietal lobes. Prior to discharge home, aspirin was discontinued and the patient was started on oral anticoagulation for secondary stroke prevention.

In this particular case, the NIHSS would not have been a helpful tool in guiding the decision to proceed with acute stroke treatment as the scale puts heavy emphasis on gross motor strength, sensation, and language and less emphasis on fine motor skills. Thus, dysgraphia/agraphia is not tested as part of the NIHSS despite it being a debilitating deficit that can result from cerebral infarction. Given that the patient had a low NIHSS and mild, nondebilitating symptoms, she may not have been considered a tPA candidate without the additional evaluation of her writing and appropriate correlation of the perfusion deficit noted on CTP. The importance of sophisticated imaging modalities beyond MRI such as perfusion imaging to provide immediate, more definitive insight into those at risk for acute cerebral ischemia is crucial. This patient was unable to undergo MRI due to AICD placement. Thus, without the availability of these additional imaging modalities, treatment decisions for the patient may have been altered. This case illustrates the importance of carefully considering patient history and examination and utilizing the most appropriate available imaging to guide treatment planning. 


\section{Author contributions}

Dr. Smith drafted the initial manuscript, revised the manuscript, and was involved in the clinical care of the patient. Dr. Roach drafted the initial manuscript, revised the manuscript, and was involved in the clinical care of the patient. Dr. Chapman Smith revised the manuscript and was involved in the clinical care of the patient.

\section{Study funding}

No targeted funding reported.

\section{Disclosure}

The authors report no disclosures relevant to the manuscript. Go to Neurology.org/N for full disclosures.

\section{References}

1. Roux FE, Dufor O, Giussani C, et al. The graphemic/motor frontal area Exner's area revisited. Ann Neurol 2009;66:537-545.

2. Keller C, Meister I. Agraphia caused by an infarction in Exner's area. J Clin Neurosci 2014;21:172-173.

3. Planton S, Jucla M, Roux FE, Démonet JF. The "handwriting brain": a meta-analysis of neuroimaging studies of motor versus orthographic processes. Cortex 2013;49: 2772-2787. 


\section{Neurology}

\section{Clinical Reasoning: A 61-year-old woman with acute onset dysgraphia LaTangela R. Smith, Necrisha N.C. Roach and Sherita Chapman Smith \\ Neurology 2019;92;e386-e391 \\ DOI 10.1212/WNL.0000000000006821}

This information is current as of January 21, 2019

\section{Updated Information \& Services}

\section{References}

Subspecialty Collections

Permissions \& Licensing

Reprints including high resolution figures, can be found at: http://n.neurology.org/content/92/4/e386.full

This article cites 3 articles, 0 of which you can access for free at: http://n.neurology.org/content/92/4/e386.full\#ref-list-1

This article, along with others on similar topics, appears in the following collection(s):

All Cerebrovascular disease/Stroke

http://n.neurology.org/cgi/collection/all_cerebrovascular_disease_strok e

Infarction

http://n.neurology.org/cgi/collection/infarction

Information about reproducing this article in parts (figures,tables) or in its entirety can be found online at:

http://www.neurology.org/about/about_the_journal\#permissions

Information about ordering reprints can be found online: http://n.neurology.org/subscribers/advertise

Neurology ${ }^{\circledR}$ is the official journal of the American Academy of Neurology. Published continuously since 1951, it is now a weekly with 48 issues per year. Copyright (O 2019 American Academy of Neurology. All rights reserved. Print ISSN: 0028-3878. Online ISSN: 1526-632X.

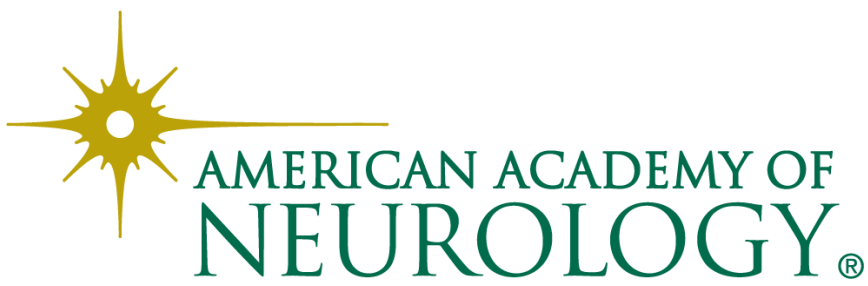

